\title{
ARCHIVES
of
}

\section{Effect of T6 Heat Treatment Parameters on Technological Quality of the AISi7Mg Alloy}

\author{
J. Pezda *, A. Jarco \\ Department of Production Engineering and Automation, University of Bielsko-Biała, \\ ul. Willowa 2, 43-300 Bielsko-Biała, Poland \\ *Corresponding author. E-mail address: jpezda@ath.bielsko.pl
}

Received 31.03.2016; accepted in revised form 04.05.2016

\begin{abstract}
Very well-known advantages of aluminum alloys, such as low mass, good mechanical properties, corrosion resistance, machining-ability, high recycling potential and low cost are considered as a driving force for their development, i.e. implementation in new applications as early as in stage of structural design, as well as in development of new technological solutions. Mechanical and technological properties of the castings made from the 3xx.x group of alloys depend mainly on correctly performed processes of melting and casting, design of a mould and cast element, and a possible heat treatment.

The subject-matter of this paper is elaboration of a diagrams and dependencies between parameters of dispersion hardening (temperatures and times of solutioning and ageing treatments) and mechanical properties obtained after heat treatment of the 356.0 (EN AC AlSi7Mg) alloy, enabling full control of dispersion hardening process to programming and obtaining a certain technological quality of the alloy in terms of its mechanical properties after performed heat treatments. Obtained results of the investigations have enabled obtainment of a dependencies depicting effect of parameters of the solutioning and ageing treatments on the mechanical properties $\left(\mathrm{R}_{\mathrm{m}}, \mathrm{A}_{5}\right.$ and $\mathrm{KC}$ impact strength) of the investigated alloy. Spatial diagrams elaborated on the basis of these dependencies enable us to determine tendencies of changes of the mechanical properties of the 356.0 alloy in complete analyzed range of temperature and duration of the solutioning and ageing operations.
\end{abstract}

Keywords: Heat treatment, Aluminum alloys, Tensile strength, Elongation, Impact strength

\section{Introduction}

Oftentimes, producers of a cast machinery parts made from the $\mathrm{Al}-\mathrm{Si}-\mathrm{Mg}, \mathrm{Al}-\mathrm{Si}-\mathrm{Cu}$ and $\mathrm{Al}-\mathrm{Si}-\mathrm{Cu} / \mathrm{Mg}$ alloys do not take full advantage of all possibilities offered by this material, in scope of its mechanical and technological properties, justifying it by economical reasons resulted from performed heat treatment process (long time of performed operations of the solutioning and ageing) and concerns about a possible partial melting of a processed component during solutioning operation, which is usually performed at temperature close to eutectic temperature of the alloy (practically, the solutioning temperature should be lower with $20-30^{\circ} \mathrm{C}$ than the eutectic temperature). Moreover, the processes occurring during artificial ageing and comprising precipitation from supersaturated solution of strengthening phases, should be also performed at increased temperature (150$260{ }^{\circ} \mathrm{C}$ ) for a specified period of time.

Many authors had taken efforts to investigate effects of temperature and time of heat treatment operations on change of microstructure and mechanical properties of the 356.0 casting alloy [1-3]. Likewise, the author of this paper has conducted research work from this area [4-6]. Normally, the ASTM B917-01 standard, for the 356.0 alloy specifies solutioning time of 6-12 hours at temperature $540{ }^{\circ} \mathrm{C}$, cooling in warm water, and next 2-5 hours at temperature $155^{\circ} \mathrm{C}$, for a castings from sand mould [7]. Instead, for a castings from metal moulds, 4-12 hours of 
solutioning at $540{ }^{\circ} \mathrm{C}$ and $2-5$ hours of ageing at temperature 155 ${ }^{\circ} \mathrm{C}[7]$.

The AFS proposes solutioning at $538{ }^{\circ} \mathrm{C}$ for 12 hours and ageing at $155{ }^{\circ} \mathrm{C}$ for $3-5$ hours in case of sand castings, and 227 ${ }^{\circ} \mathrm{C}$ for a die castings [8]. Zolotorevsky [9] for the AK7 alloy reports solutioning temperature $535{ }^{\circ} \mathrm{C}$, solutioning time 2-7 hours and ageing at temperature $150{ }^{\circ} \mathrm{C}$ for $1-3$ hours. Temperature close to the solutioning $\left(535-540{ }^{\circ} \mathrm{C}\right)$, but longer solutioning time ( 8 hours for a castings from metal moulds and 12 hours, for a castings from sand moulds) and ageing at 150-155 ${ }^{\circ} \mathrm{C}$ for $2-5$ hours is reported by the authors of $[10,11]$. Davidson in his study [12], reducing time of the solutioning from 8 to 4 hours, did not notice any effect on its fatigue strength. According to Shivkumar [13], solutioning for 3-6 hours at temperature 540 ${ }^{\circ} \mathrm{C}$ is optimal for modified alloy, poured to sand moulds. However, D. Emadi [14] had shown in his investigations that solutioning time of 4 hours at $540{ }^{\circ} \mathrm{C}$ assures optimal properties, while Yoshida [15] had obtained the highest hardness during short time of the solutioning ( 2 hours at $520{ }^{\circ} \mathrm{C} / 540{ }^{\circ} \mathrm{C}$ and ageing at $160{ }^{\circ} \mathrm{C}$ for 6,5 hour). Pedersen [1] had obtained maximal strength as early as after 60 minutes of solutioning at $540{ }^{\circ} \mathrm{C}$ and four hours ageing at $150{ }^{\circ} \mathrm{C}$, while prolongation of time of the treatment did not lead to increase of the strength.

Zhang in the study [16] says that solutioning for 10 minutes at $540{ }^{\circ} \mathrm{C}$ or $550{ }^{\circ} \mathrm{C}$ is sufficient to reach maximal level of magnesium and silicone, as anticipated in limits of solubility and composition of the alloy. Treatment for 30 minutes results in spheroidization and increased space between precipitations of eutectic silicone. It leads to considerable improvement of ductility and impact strength. Comparing with standard process of the solutioning for 6 hours, 30 minutes of the solutioning at temperature 540 and $550{ }^{\circ} \mathrm{C}$ is sufficient to reach more than $90 \%$ of the $\mathrm{R}_{0,2}$ and not more than $95 \%$ of the $\mathrm{R}_{\mathrm{m}}$. Similar mechanical properties were obtained by Peng [17], however after solutioning at $550{ }^{\circ} \mathrm{C}$ for 2 hours and ageing at $170{ }^{\circ} \mathrm{C}$ also for 2 hours.

On the basis of the above results it can be ascertained that there exist a pretty big discrepancies concerning ranges of the temperature and duration of the solutioning and ageing operations, however, shortening of these durations is possible without any considerable effect on obtained mechanical properties of the 356.0 aluminum alloy.

As the main problem emerges determination of a range of temperature and time of individual operations, enabling obtainment of suitable mechanical properties of the alloy.

In the paper is presented heat treatment process of a test pieces produced from the 356.0 alloy, which was performed of the basis of specified range of the parameters aimed at obtainment of significant improvement of mechanical properties of the material, with consideration of economical aspect of the performed process (limitation of temperature and time of the solutioning and ageing operations), and are presented elaborated dependencies and spatial diagrams plotted on the basis of such dependencies, which describe effect of parameters of the solutioning and ageing treatments on the mechanical properties $\left(\mathrm{R}_{\mathrm{m}}, \mathrm{A}_{5}\right.$ and $\mathrm{KC}$ impact strength) of the investigated alloy, as well as depicting tendencies of changes of its mechanical properties in complete analyzed range of time and temperature of the solutioning and ageing treatments.

\section{Methodology of the research}

Perfect ductility, corrosion resistance and high ratio of the strength to the mass make that the 356.0 alloy from the Al-Si-Mg group is suitable to various applications within automotive industry, such as cylinder blocks and heads, wheel rims, and complex thin-wall elements produced in casting process with use of metal and sand moulds, having strength up to $350 \mathrm{MPa}[6,9$, 18-19]. Chemical composition of the investigated alloy is presented in the Table 1 .

Table 1

Chemical composition of the 356.0 (EN AC-AlSi7Mg) alloy Chemical composition / mass \%

\begin{tabular}{ccccc}
\hline $\mathrm{Si}$ & $\mathrm{Cu}$ & $\mathrm{Zn}$ & $\mathrm{Fe}$ & $\mathrm{Mg}$ \\
\hline 7,2 & 0,27 & 0,3 & 0,65 & 0,3 \\
\hline \hline $\mathrm{Ni}$ & $\mathrm{Mn}$ & $\mathrm{Pb}$ & $\mathrm{Cr}$ & $\mathrm{Al}$ \\
\hline 0,1 & 0,27 & 0,02 & 0,07 & rest
\end{tabular}

Analysis of the chemical composition was performed using an optical emission spectrometry method, with inductively coupled plasma on the PerkinElmer optical emission spectrometer, Optima 4300 Dv model, in the Bosmal R\&D Institute in Bielsko-Biala.

To produce the test pieces, which were used in course of the investigations, the alloy was melted in electric resistance furnace at temperature of $720-750^{\circ} \mathrm{C}$. In the next stage it has been performed refining treatment with use of refining preparation (Rafal 1), in quantity $0,4 \%$ mass of the charge. Refined alloy, after removal of oxides and slag from the metal level, was modified with the AlSr10 master alloy, in quantity of $0,5-0,6 \%$ mass of the charge. Temperature of the liquid alloy was maintained at the level of $720-740{ }^{\circ} \mathrm{C}$.

The Al-Si casting alloys, in most cases, are the product being result of recycling. There exists, therefore, a danger connected with possibility of partial melting of heat treated machinery parts, due to presence of low melting phases and inter-metallic compounds, and changes in temperature of melting process.

A solution in such case could be the ATD method, serving to recording of crystallization course of metals and alloys. Information obtained on the basis of curves from the ATD method make possible not only to determine, with a high accuracy, melting temperature of a given alloy, but also melting temperatures present in the alloy of low melting phases. This method has enabled initial selection of range of temperatures of the solutioning and ageing operations (Fig. 1) used in assumed trivalent plan of the investigations with four variables. 


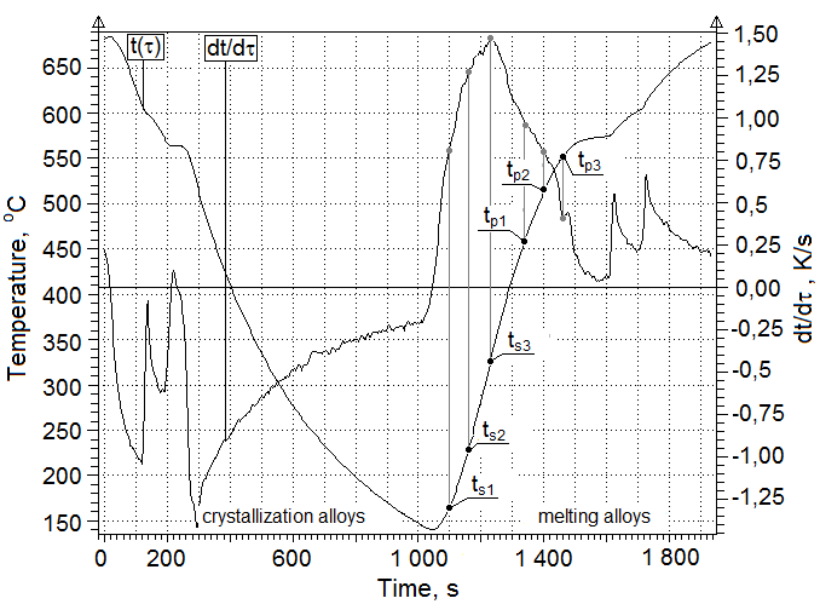

Fig. 1. ATD diagram of the investigated alloy

On curves from the ATD method (Fig. 1) are marked characteristic points having values denoting temperatures of the solutioning and ageing operations, implemented in the assumed plan of the investigations. In the Table 2 are presented parameters of solutioning and ageing for performed heat treatment operation of the investigated alloy.

Table 2 .

Heat treatment parameters of the 356.0 alloy

\begin{tabular}{|c|c|c|c|}
\hline $\begin{array}{c}\text { solutioning } \\
\text { temperature } \\
\mathrm{t}_{\mathrm{p}},{ }^{\circ} \mathrm{C}\end{array}$ & $\begin{array}{l}\text { solutioning } \\
\text { time } \\
\tau_{\mathrm{p}}, \mathrm{h}\end{array}$ & $\begin{array}{c}\text { ageing } \\
\text { temperature } \\
\mathrm{t}_{\mathrm{s}},{ }^{\circ} \mathrm{C}\end{array}$ & $\begin{array}{c}\text { ageing time } \\
\tau_{\mathrm{s}}, \mathrm{h}\end{array}$ \\
\hline$t_{p 1}-465$ & 0,5 & $\mathrm{t}_{\mathrm{s} 1}-165$ & 2 \\
\hline$t_{p 2}-520$ & 1,5 & $t_{s 1}-235$ & 5 \\
\hline$t_{p 3}-550$ & 3 & $t_{s 1}-325$ & 8 \\
\hline
\end{tabular}

Standardized test pieces were poured in a mould produced according with the $\mathrm{PN}-88 / \mathrm{H}-88002$ standard, while the test pieces to impact test were poured in a mould produced for simplified impact test [20]. The heat treatment consisted of solutioning, followed by rapid cooling of the test pieces in water at temperature $20{ }^{\circ} \mathrm{C}$ and artificial ageing with cooling at the air.

Solutioning operations were performed in a resistance furnace. Measurement of the temperature was performed continuously with use of $\mathrm{Ni}-\mathrm{NiCr}$ thermoelements of type $\mathrm{K}$, with accuracy $\pm 5^{\circ} \mathrm{C}$ directly in chamber of the furnace.

After performed heat treatment, the test pieces to measurement of the tensile strength $\mathrm{R}_{\mathrm{m}}$ and elongation $\mathrm{A}_{5}$ were prepared according with the PN-EN ISO 6892-1:2010P standard (the test piece with measuring length of $50 \mathrm{~mm}$ and diameter of $10 \mathrm{~mm}$ ). Static tensile tests were performed according with the PN-EN ISO 6892-1:2010P standard, on the strength tester of the ZD-20 type. Measurement of the Brinell hardness was performed according to the PN-EN ISO 6506-1:2008P standard, with use of the Brinell hardness tester of the PRL 82 type, with steel ball having $10 \mathrm{~mm}$ diameter, under load $9800 \mathrm{~N}$, sustained for 30 seconds. The hardness of the poured test pieces was measured on grip sections of milled test pieces to the strength tests.
Determination of the impact strength of casting alloys was made basing on the simplified method [20], with use of the Charpy pendulum machine, with use of the test pieces having incised cylindrical notch.

In such case, the impact strength denotes ratio of the work used to rupture of the test piece (in J) to surface area of cross section in place of the notch (in $\mathrm{cm}^{2}$ ). Obtained in such way results can not be compared with results of the standardized tests [20].

The software package "Statistica" ver. 10 of the StatSoft Company was used to obtain the dependencies and plot the diagrams showing effect of the heat treatment parameters on the mechanical properties of the investigated alloys

\section{Description of obtained results}

\subsection{Tensile strength $R_{m}$}

Tensile strength of the raw alloy (from pig sows) amounted to $190 \mathrm{MPa}$. After refinement there occurred a slight change (199 $\mathrm{MPa}$ ), while performed treatment of modification has enabled obtainment of the $\mathrm{R}_{\mathrm{m}}$ within limits 200-205 MPa.

After performed heat treatment of the alloy, obtained tensile strength $\mathrm{R}_{\mathrm{m}}$ amounted from 154 to $335 \mathrm{MPa}$.

Making comparison of obtained values of the $R_{m}$ strength for the alloy after heat treatment and without the heat treatment (Fig. 2 ) it has been ascertained the highest increase of the $R_{m}$ strength for the systems: $13\left(\mathrm{t}_{\mathrm{p}}=520{ }^{\circ} \mathrm{C} ; \tau_{\mathrm{p}}=1,5\right.$ hour; $\mathrm{t}_{\mathrm{s}}=165{ }^{\circ} \mathrm{C} ; \tau_{\mathrm{s}}=5$ hours), system $19\left(\mathrm{t}_{\mathrm{p}}=550{ }^{\circ} \mathrm{C} ; \tau_{\mathrm{p}}=0,5\right.$ hour; $\mathrm{t}_{\mathrm{s}}=165{ }^{\circ} \mathrm{C} ; \tau_{\mathrm{s}}=5$ hours) and the system $25\left(\mathrm{t}_{\mathrm{p}}=550{ }^{\circ} \mathrm{C} ; \tau_{\mathrm{p}}=3\right.$ hours; $\mathrm{t}_{\mathrm{s}}=165{ }^{\circ} \mathrm{C} ; \tau_{\mathrm{s}}=$ 8 hours). Slightly lower tensile strength, within limits of 300 $\mathrm{MPa}$, was obtained for the systems 4, 16 and 22 characteristic of, similarly like in case of the systems 13,19 and 25 , with low ageing temperature $\left(\mathrm{t}_{\mathrm{s}}=165^{\circ} \mathrm{C}\right)$ during 2 to 8 hours.

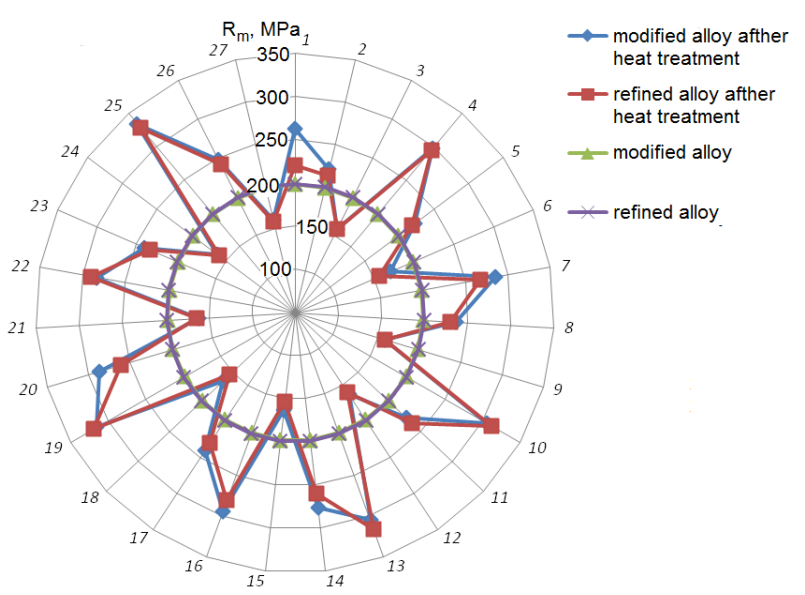

Fig. 2. Tensile strength $R_{m}$ of the investigated alloy

The lowest tensile strength $R_{m}$ was obtained for the systems 3 , 9 and 27, which were characteristic of high ageing temperature $\left(t_{s}=325^{\circ} \mathrm{C}\right)$, in complete range of ageing times. Obtained value of the $\mathrm{R}_{\mathrm{m}}$ for these systems amounting to $158-163 \mathrm{MPa}$ constitutes 
its distinct decrease with respect to the alloy without the heat treatment. Results of performed investigations have enabled development of dependencies (1), in form of second order polynomial, describing effect of the heat treatment parameters on change of the $\mathrm{R}_{\mathrm{m}}$ strength of the investigated alloy.

$$
\begin{aligned}
& R_{m}=-64,66+0,738 t_{p}+2,53 \cdot 10^{-4} t_{p}^{2}+60,855 \tau_{p}-0,844 \tau_{p}^{2}+0,655 t_{s} \\
& -2,41 \cdot 10^{-4} t_{s}^{2}+7,64 \tau_{s}+0,364 \tau_{s}^{2}-0,105 t_{p} \tau_{p}-22,68 \cdot 10^{-4} t_{p} t_{s}-0,007 t_{p} \tau_{s} \\
& -0,027 \tau_{p} t_{s}+0,805 \tau_{p} \tau_{s}-0,036 t_{s} \tau_{s}
\end{aligned}
$$

where: $t_{p}$ - solutioning temperature, $\tau_{p}$ - solutioning time, $t_{s}-$ ageing temperature, $\tau_{s}$ - ageing time. Coefficients of: correlation $\mathrm{R}=0,99$; determination $\mathrm{R}^{2}=0,98$; correction. $\mathrm{R}^{2}=0,95$.

Effect of temperature and time of the solutioning and ageing operations of performed heat treatment operations on change of the tensile strength $R_{m}$, is presented in graphical form on spatial diagrams (Fig. 3). For the solutioning operation it has been taken constant values of the ageing parameters: temperature $t_{s}=165^{\circ} \mathrm{C}$ and time $\tau_{\mathrm{s}}=5$ hours, while for the operation of the ageing, fixed parameters of the solutioning operation are: temperature $t_{p}=520$ ${ }^{\circ} \mathrm{C}$ and time $\tau_{\mathrm{s}}=1$ hour.
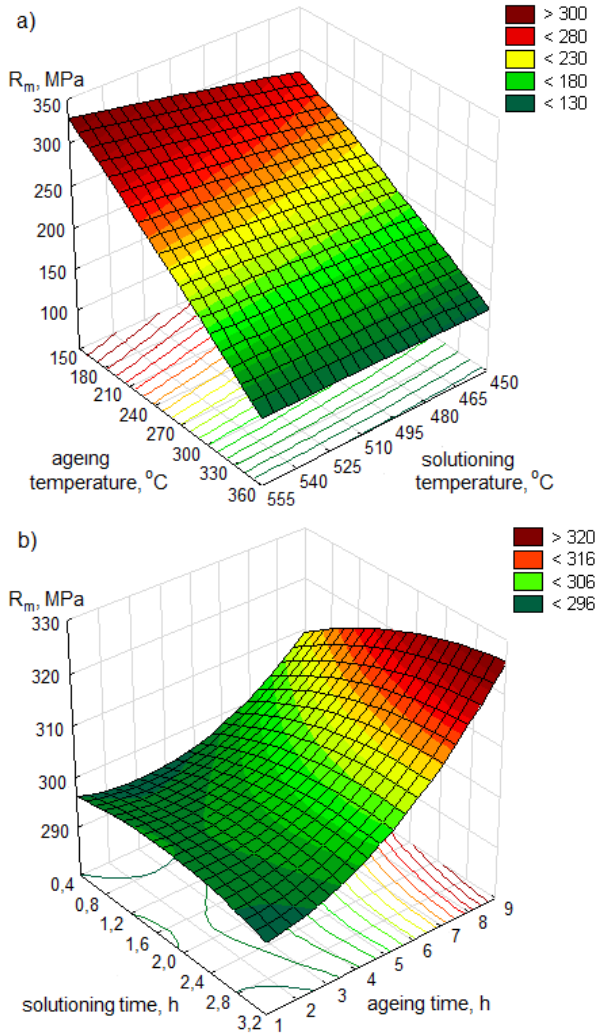

Fig. 3. Effect of parameters of the solutioning and ageing operations on the tensile strength $R_{m}:$ a) $t_{s}$ and $\left.t_{p}, b\right) \tau_{p}$ and $\tau_{s}$

Obtainment of maximal increase of the tensile strength $R_{m}$ of the alloy is possible after its solutioning at temperature $t_{p}=520$ $550{ }^{\circ} \mathrm{C}$ for 1 to 3 hours, and next, cooling in cold water and ageing for 5 to 8 hours at temperature $\mathrm{t}_{\mathrm{s}}=165^{\circ} \mathrm{C}$.

\subsection{Elongation $\mathbf{A}_{5}$}

Value of the elongation $\mathrm{A}_{5}$, obtained for the raw alloy (from pig sows), amounted to $5,4 \%$. After refinement there occurred a slight change of the elongation $(5,7 \%)$. Performed treatment of modification of the investigated alloy has enabled obtainment of the elongation $\mathrm{A}_{5}=6,5 \%$, whereas performed heat treatment resulted in change of the elongation $A_{5}$ within range of 3,7 to 15,6 $\%$.

Making comparison of obtained values of the elongation $\mathrm{A}_{5}$ for the alloy after heat treatment and the alloy without the heat treatment (Fig. 4), it has been ascertained the highest increase of the elongation $\mathrm{A}_{5}$ for the system 9 (solutioning temperature $-t_{p}=$ $465{ }^{\circ} \mathrm{C}$; solutioning time $-\tau_{\mathrm{p}}=0,5$ hour; ageing temperature $-\mathrm{t}_{\mathrm{s}}=$ $325{ }^{\circ} \mathrm{C}$; ageing time $-\tau_{\mathrm{s}}=8$ hours $)$, system $15\left(\mathrm{t}_{\mathrm{p}}=520{ }^{\circ} \mathrm{C} ; \tau_{\mathrm{p}}=1,5\right.$ hour; $\mathrm{t}_{\mathrm{s}}=325{ }^{\circ} \mathrm{C} ; \tau_{\mathrm{s}}=8$ hours $)$ and system $24\left(\mathrm{t}_{\mathrm{p}}=550{ }^{\circ} \mathrm{C} ; \tau_{\mathrm{p}}=1,5\right.$ hour; $\mathrm{t}_{\mathrm{s}}=325{ }^{\circ} \mathrm{C} ; \tau_{\mathrm{s}}=5$ hours). The smallest elongation $\mathrm{A}_{5}$ was obtained for the test pieces from the systems 4,7 and 10 , characteristic of low ageing temperature $\left(t_{s}=165^{\circ} \mathrm{C}\right)$, during 5 to 8 hours. Obtained elongation $\mathrm{A}_{5}$ for these systems, comparing with the input alloy (without the heat treatment), is smaller with $30-40 \%$.

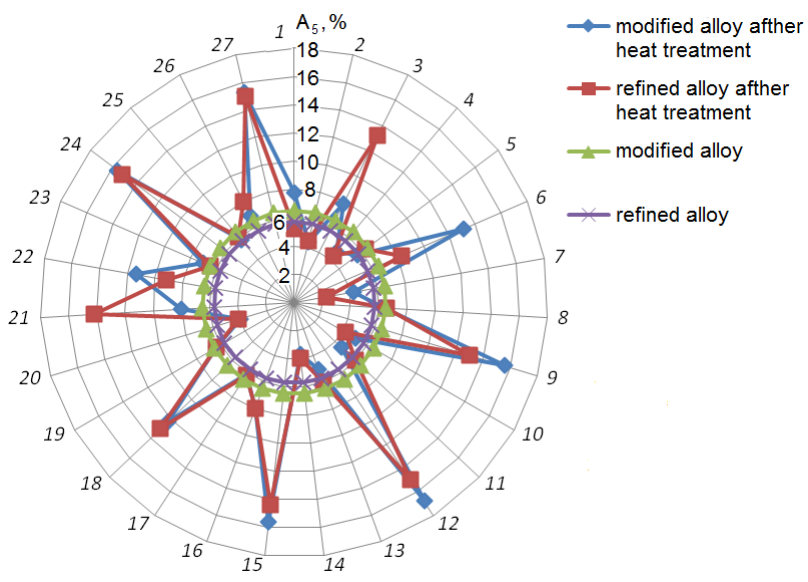

Fig. 4. Elongation $\mathrm{A}_{5}$ of the 356.0 alloy

Obtained results have enabled development of the dependencies (2) in form of second order polynomial, describing effect of heat treatment parameters on change of the elongation $A_{5}$ of the investigated alloy.

$$
\begin{aligned}
& A_{5}=234,75-0,789 t_{p}+7,94 \cdot 10^{-4} t_{p}^{2}-1,436 \tau_{p}-0,382 \tau_{p}^{2}-0,269 t_{s} \\
& +5,83 \cdot 10^{-4} t_{s}^{2}-2,107 \tau_{s}-0,087 \tau_{s}^{2}+0,002 t_{p} \tau_{p}-0,17 \cdot 10^{-4} t_{p} t_{s} \\
& +0,0003 t_{p} \tau_{s}+0,009 \tau_{p} t_{s}+0,012 \tau_{p} \tau_{s}+0,003 t_{s} \tau_{s}
\end{aligned}
$$

where: $t_{p}$ - solutioning temperature, $\tau_{p}$ - solutioning time, $t_{s}$ ageing temperature, $\tau_{s}$ - ageing time. Coefficients of: correlation $\mathrm{R}=0,97$; determination $\mathrm{R}^{2}=0,94$; correction. $\mathrm{R}^{2}=0,87$.

In the Fig. 5 is presented effect of temperature and time of the solutioning and ageing operations on change of the elongation $\mathrm{A}_{5}$ of the investigated alloy at constant parameters of the ageing $\left(t_{s}=\right.$ $165^{\circ} \mathrm{C}$ and $\tau_{\mathrm{s}}=5$ hours) in case of the solutioning, and constant 
parameters of the solutioning $\left(t_{p}=520^{\circ} \mathrm{C}\right.$ and $\tau_{p}=1$ hour $)$ for the operation of ageing.
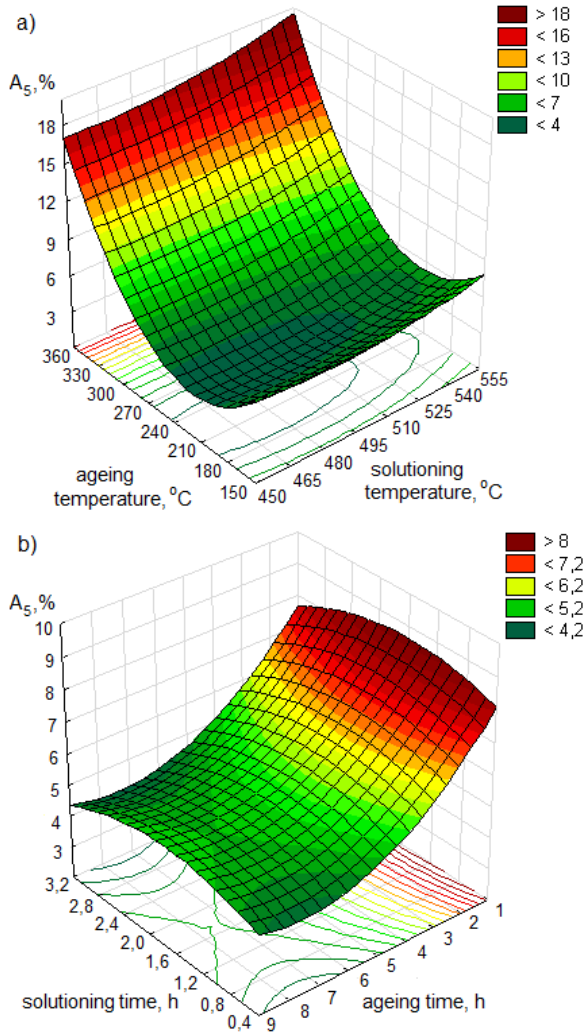

Fig. 5. Effect of the solutioning and ageing parameters on the elongation $\mathrm{A}_{5}$ of the 356.0 alloy: a) $\mathrm{t}_{\mathrm{s}}$ and $\left.\mathrm{t}_{\mathrm{p}}, \mathrm{b}\right) \tau_{\mathrm{p}}$ and $\tau_{\mathrm{s}}$

\subsection{Impact strength $\mathrm{KC}$}

Impact strength of the raw alloy (from pig sows) amounted to $5,4 \mathrm{~J} / \mathrm{cm}^{2}$. After refinement had occurred a slight change of the impact strength $-5,7 \mathrm{~J} / \mathrm{cm}^{2}$. Performed treatment of modification of the investigated alloy did not have any considerable effect on change of the impact strength, which was included within range of 5,8 to $6,2 \mathrm{~J} / \mathrm{cm}^{2}$. Impact strength of modified alloy after the heat treatment was changing within range from 4,2 to $27,5 \mathrm{~J} / \mathrm{cm}^{2}$.

Making comparison of obtained values of the impact strength of the alloy after the heat treatment and the alloy without the heat treatment (Fig. 6), it has been confirmed that the biggest increase of the impact strength is seen for the following systems: system 18 (solutioning temperature $-\mathrm{t}_{\mathrm{p}}=520^{\circ} \mathrm{C}$; solutioning time $-\tau_{\mathrm{p}}=3$ hours; ageing temperature $-\mathrm{t}_{\mathrm{s}}=325^{\circ} \mathrm{C}$; ageing time $-\tau_{\mathrm{s}}=2$ hours) and the system $27\left(\mathrm{t}_{\mathrm{p}}=550{ }^{\circ} \mathrm{C} ; \tau_{\mathrm{p}}=3\right.$ hours; $\mathrm{t}_{\mathrm{s}}=325{ }^{\circ} \mathrm{C} ; \tau_{\mathrm{s}}=2$ hours). The lowest impact strength was obtained for the test pieces from the systems 10 and 25 , characteristic of low ageing temperature $\left(\mathrm{t}_{\mathrm{s}}=165^{\circ} \mathrm{C}\right)$ during 8 hours.

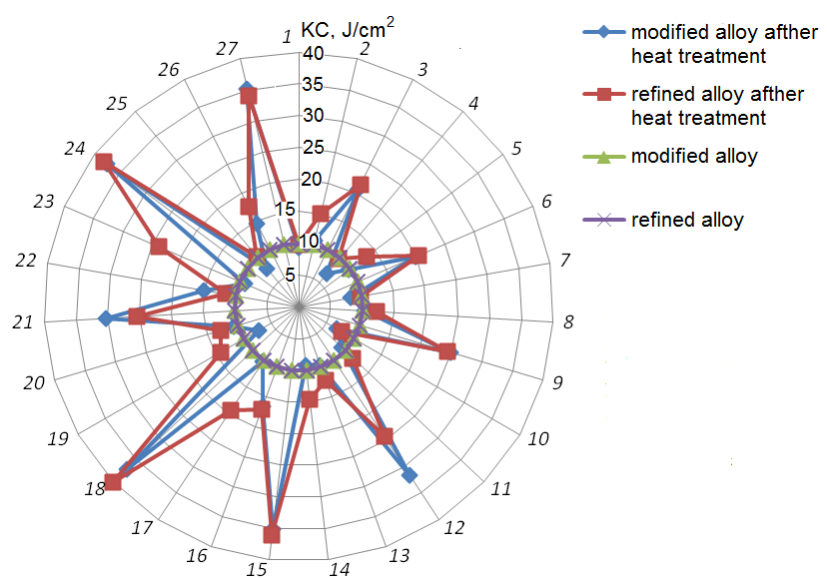

Fig. 6. Impact strength $\mathrm{KC}$ of the 356.0 alloy

Results of the performed investigations have enabled elaboration of the dependencies (3) in form of second order polynomial, describing effect of the heat treatment parameters on change of the impact strength $\mathrm{KC}$ of the investigated alloy.

$$
\begin{aligned}
& K C=-16,596+0,335 t_{p}-4,44 \cdot 10^{-4} t_{p}^{2}+4,492 \tau_{p}-0,308 \tau_{p}^{2}-0,66 t_{s} \\
& +8,73 \cdot 10^{-4} t_{s}^{2}+1,088 \tau_{s}-0,060 \tau_{s}^{2}-0,012 t_{p} \tau_{p}+6,03 \cdot 10^{-4} t_{p} t_{s} \\
& +0,001 t_{p} \tau_{s}+0,004 \tau_{p} t_{s}-0,173 \tau_{p} \tau_{s}+0,002 t_{s} \tau_{s}
\end{aligned}
$$

where: $t_{p}$ - solutioning temperature, $\tau_{p}$ - solutioning time, $t_{s}$ ageing temperature, $\tau_{s}$ - ageing time. Coefficients of: correlation $\mathrm{R}=0,98$; determination $\mathrm{R}^{2}=0,97$; correction. $\mathrm{R}^{2}=0,93$.

In the Figs. 7-8 is presented effect of temperature and time of the solutioning operation on change of the impact strength of the investigated alloy at constant parameters of the ageing $\left(\mathrm{t}_{\mathrm{s}}=165^{\circ} \mathrm{C}\right.$ and $\tau_{\mathrm{s}}=5$ hours), as well as effect of temperature and time of the ageing on change of the impact strength of the alloy at constant parameters of the solutioning $\left(\mathrm{t}_{\mathrm{p}}=520^{\circ} \mathrm{C}\right.$ i $\tau_{\mathrm{p}}=1$ hour $)$.

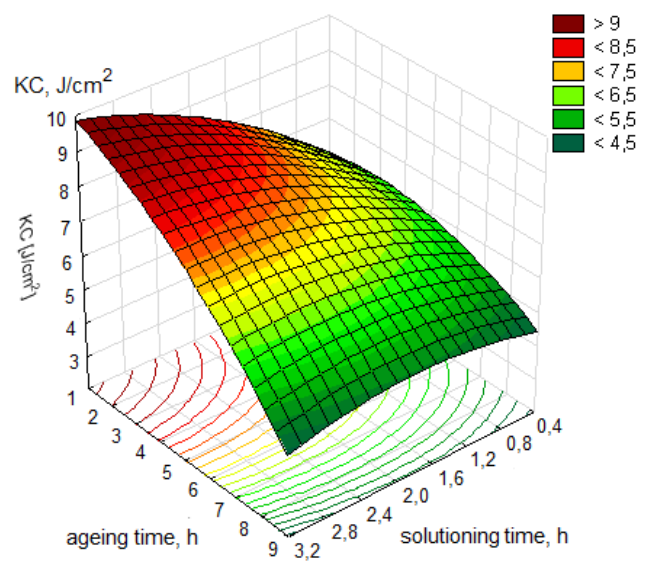

Fig. 7. Effect of time of the solutioning and ageing on the impact strength $\mathrm{KC}$ of the 356.0 alloy 


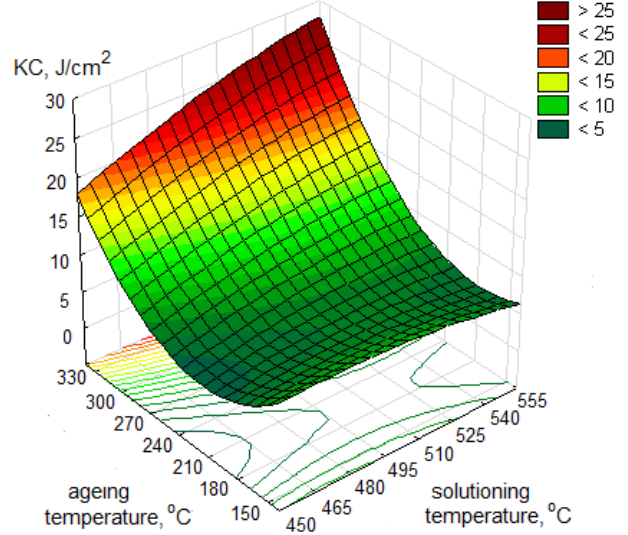

Fig. 8. Effect of temperature of the solutioning and ageing on the impact strength $\mathrm{KC}$ of the 356.0 alloy

The highest value of the impact strength was obtained for the test pieces solutioned at temperature $t_{p}=520-550{ }^{\circ} \mathrm{C}$, for 1,5 to 3 hours, cooled in water, and next aged at temperature $t_{\mathrm{s}}$ above 300 ${ }^{\circ} \mathrm{C}$, for 2 to 5 hours. Ageing temperature within limits of 160-240 ${ }^{\circ} \mathrm{C}$ have an adverse effect on the impact strength of the 356.0 alloy, resulting in its decrease comparing to the alloy without the heat treatment.

\section{Conclusions}

Developed methodology of the investigations, concerning heat treatment of the commercial 356.0 (AlSi7Mg) alloy has enabled determination (selection) of the solutioning and ageing parameters, assuring considerable improvement of their mechanical properties.

Obtained results of the investigations have enabled obtainment of the dependencies describing effect of the solutioning and the ageing parameters on the mechanical properties $\left(\mathrm{R}_{\mathrm{m}}, \mathrm{A}_{5}\right.$, and impact strength $\mathrm{KC}$ ) for the 356.0 alloy. Spatial diagrams plotted on their basis enable determination of a trends of changes of its mechanical properties in complete analyzed range of time and temperature of the solutioning and the ageing treatments.

\section{References}

[1] Pedersen, L. \& Arnberg. L. (2001).The effect of solution heat treatment and quenching rates on mechanical properties and microstructures in AlSiMg foundry alloys. Metallurgical and Materials Transactions A. 32(3), 525-532. DOI: 10.1007/s11661-001-0069-y.

[2] Górny, Z., Kluska-Nawarecka, S., Czekaj, E., WilkKołodziejczyk, D. \& Saja, K. (2104). Heuristic Model of the Mechanical Properties of a Hypoeutectic EN AC-42100 (EN AC-AlSi7Mg0.3) Silumin Alloy Subjected to Heat Treatment. Archives of Foundry Engineering. 14(4), 35-38.

[3] Orłowicz, W., Tupaj, M. \& Mróz, M. (2006). Selecting of heat treatment parameters for AlSi7Mg0,3 alloy. Archives of Foundry. 6(22), 350-357. (in Polish).
[4] Pezda, J. (2014). Influence of heat treatment parameters on the mechanical properties of hypoeutectic Al-Si-Mg alloy. Metalurgija. 53(2), 221-224.

[5] Pezda, J. (2011). Effect of T6 heat treatment on mechanical properties and microstructure of $\mathrm{EN}$ AB-42000 alloy modified with strontium. Archives of Foundry Engineering. 11(2), 169-174.

[6] Pezda J. (2014). Effect of selected parameters of the heat treatment operations on technological quality of machinery components pored from silumins. Bielsko-Biała: Scientific Publication of ATH. (in Polish).

[7] ASTM Standard B917/B917M-2001: Standard Practice for Heat Treatment of Aluminum-Alloy Castings from All Processes.

[8] Metalcaster's Reference \& Guide. (1989). Des Plaines: American Foundry Society.

[9] Zolotorevsky, V.S., Belov, N.A. \& Glazoff, M.V. (2007). Casting Aluminium Alloys. Oxford: Elsevier.

[10] Davis, J. R. (1993). Aluminium and aluminium alloys. ASM Speciality Handbook, Ohio: ASM International.

[11] ASM handbook. (1991). Heat treating. Ohio: ASM International.

[12] Davidson, C.J., Griffiths, J.R. \& Machin, A.S. (2002). The Effect of Solution Heat-Treatment Time on the Fatigue Properties of an Al-Si-Mg Casting Alloy. Fatigue \& Fracture of Engineering Materials \& Structures. 25, 223230. DOI: $10.1046 /$ j.8756-758x.2001.00490.x

[13] Shivkumar, S., et al. (1989). An experimental study to optimize the heat treatment of A356 alloy. AFS Transactions. 97, 791-810.

[14] Emadi, D., Whiting, L.V. \& Sahoo, M. (2003). Optimal Heat Treatment of A356.2 Alloy. Light Metals, The Minerals, Metals and Materials Society. 983-989.

[15] Yoshida, K.A., \& Arrowood, R.M. (1995). Microstructure and mechanical properties of A356 aluminum castings as related to various T6-type heat treatments. In TMS Annual Meeting. (pp. 77-88). Warrendale, PA, United States: Minerals, Metals \& Materials Soc (TMS).

[16] Zhang, D.L. \& Zheng, L. (1996). The Quench Sensitivity of Cast Al-7 Wt Pct Si-0.4 Wt Pct Mg Alloy. Metallurgical and Materials Transactions A. 27(12), 3983-3991. DOI: 10.1007/BF02595647

[17] Peng, J., Tang, X., He, J. \& Xu, D. (2011). Effect of heat treatment on microstructure and tensile properties of A356 alloys. Transactions of Nonferrous Metals Society of China. 21(9), 1950-1956. DOI:10.1016/S1003-6326(11)60955-2.

[18] Merlin, M. \& Garagnani, G.L. (2009). Mechanical and microstructural characterisation of A356 castings realised with full and empty cores. Metallurgical Science and Technology. 27(1), 21-30.

[19] Möller, H., Govender, G. \& Stumpf, W.E. (2010). Application of shortened heat treatment cycles on A356 automotive brake calipers with respective globular and dendritic microstructures. Transactions Nonferrous Metals Society of China. 20(9) 1780-1785. DOI:10.1016/S10036326(09)60374-5

[20] Poniewierski Z. (1989). Crystallization, structure and properties of silumins. Warszawa: WNT. (in Polish) 